\section{U.S. DEPARTMENT OF ENERGY}

\section{Office of}

ENERGY EFFICIENCY \& RENEWABLE ENERGY

\title{
Room Return Path Sensitivity
}

July 2021 


\section{Disclaimer}

This work was prepared as an account of work sponsored by an agency of the United States Government. Neither the United States Government nor any agency thereof, nor any of their employees, nor any of their contractors, subcontractors or their employees, makes any warranty, express or implied, or assumes any legal liability or responsibility for the accuracy, completeness, or any third party's use or the results of such use of any information, apparatus, product, or process disclosed, or represents that its use would not infringe privately owned rights. Reference herein to any specific commercial product, process, or service by trade name, trademark, manufacturer, or otherwise, does not necessarily constitute or imply its endorsement, recommendation, or favoring by the United States Government or any agency thereof or its contractors or subcontractors. The views and opinions of authors expressed herein do not necessarily state or reflect those of the United States Government or any agency thereof, its contractors or subcontractors.

Available electronically at Office of Scientific and Technical Information website (osti.gov)

Available for a processing fee to U.S. Department of Energy and its contractors, in paper, from:

U.S. Department of Energy

Office of Scientific and Technical Information

P.O. Box 62

Oak Ridge, TN 37831-0062

OSTI osti.gov

Phone: 865.576 .8401

Fax: 865.576.5728

Email: reports@osti.gov

Available for sale to the public, in paper, from:

U.S. Department of Commerce

National Technical Information Service

5301 Shawnee Road

Alexandria, VA 22312

NTIS ntis.gov

Phone: 800.553 .6847 or 703.605 .6000

Fax: 703.605.6900

Email: orders@ntis.gov 


\title{
Room Return Path Sensitivity
}

\author{
Prepared by: \\ Andrew Poerschke, IBACOS \\ Prepared for: \\ Building Technologies Office \\ Office of Energy Efficiency and Renewable Energy \\ U.S. Department of Energy
}

July 2021

NREL Technical Monitor: Conor Dennehy 


\section{Acknowledgments}

This report was funded by the Residential Buildings Integration program within the U.S. Department of Energy, Office of Energy Efficiency and Renewable Energy, Building Technologies Office.

\section{Table of Contents}

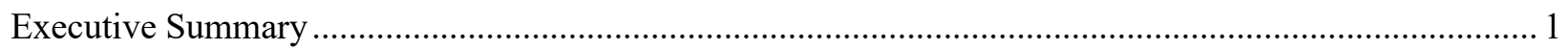

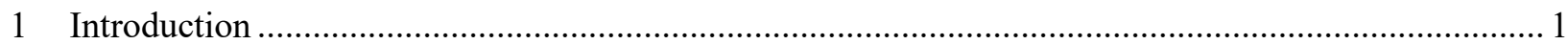

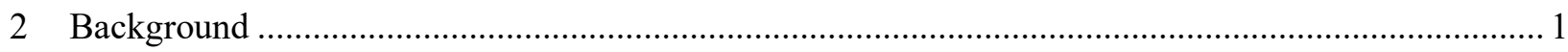

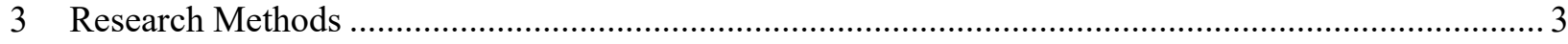

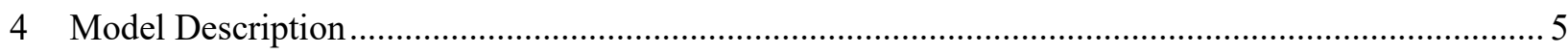

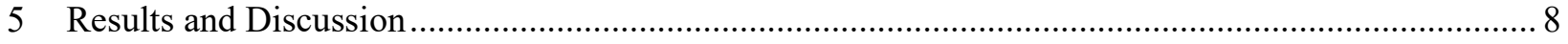

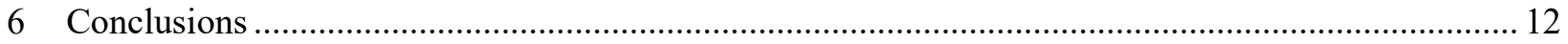

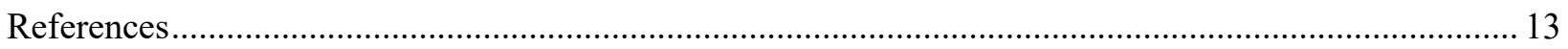




\section{Executive Summary}

Bringing heating, ventilating, and air-conditioning (HVAC) ductwork inside conditioned space is an effective strategy to achieve greater levels of energy efficiency in homes. However, doing so may impact the choice of return and supply air strategies to better fit within the home, which in turn could impact airflow balance between rooms and the delivery of optimal comfort to occupants. This report evaluates modeled scenarios using different supply and return air distribution strategies to quantify airflow balance and comfort delivery to rooms in a home when the doors to the rooms are open and closed. A home-run supply duct system was found to best maintain airflow balance when bedroom doors were closed and door undercuts were used as a return air pathway. Distributed ducted returns and systems with sufficient return air pathways eliminated this airflow balance sensitivity regardless of supply system.

\section{Introduction}

Energy codes and consumer demand are pushing homebuilders to reach greater levels of energy efficiency. Optimizing HVAC air distribution systems and bringing all ductwork into conditioned space can help builders affordably meet energy codes. This practice can have minimal cost implications, yet the impact on energy efficiency is significant, with HVAC energy savings of up to $20 \%$ depending on the climate and home (Lubliner et al. 2008, Fonorow et al. 2010). However, effectively bringing ductwork into conditioned space requires rethinking conventional design and installation practices. New best practices may challenge existing industry norms and require quantifiable evaluation involving lab and field research. This work uses building airflow models to predict room airflow balance consistency given different HVAC air distribution topologies and the effect of restricting the return air pathway (i.e., closing bedroom doors).

\section{Background}

Standard practice for HVAC return design has evolved from running a dedicated return to each room with a supply, to systems with returns in more centrally located areas of the home with jump ducts, transfer grilles, or simply door undercuts used as return air pathways from isolated rooms (NREL 2006). In these new systems, hallways and stairwells act as large open ducts for conveying air back to a single (or sometimes multiple) central return. When partition doors to an isolated room are closed, the return airflow resistance goes up, significantly impacting airflow balance if an adequate relief pathway is not installed. Airflow imbalances can lead to comfort and building durability issues as well as increased envelope leakage. To combat this, some jurisdictions have requirements for return air pathways.

The supply system topology_or layout —impacts the airflow balance stability in response to adjustments of return pathway resistances. Branching supply topologies typically have reduced static pressure after each split. The static pressure at the final split will be lower than the primary 
supply plenum. Because of this, if there is a restriction in a room's return path, supply airflow will tend to redistribute to adjacent ducts at the end of the branch. A properly designed trunk and branch supply system can effectively equalize static pressure by reducing the cross-sectional area after each takeoff (ACCA 2016). Maintaining static pressure within the trunk will reduce the system's sensitivity to changes in return paths. However, in practice, it is difficult to design and time-consuming to install a complex supply plenum. Velocity effects and poor takeoff placement also impact airflow balance.

This report considers return systems in three main categories: (1) distributed, with a return duct to each room; (2) multiple central, with one return grille on each floor of a home; and (3) single central, with a single return grille located near the air handling unit. Three supply categories are also considered: (1) radial splitter box, (2) trunk and branch, and (3) home-run, with all ducts connecting directly to a central manifold. A diagram of each supply topology is shown in the following figure.

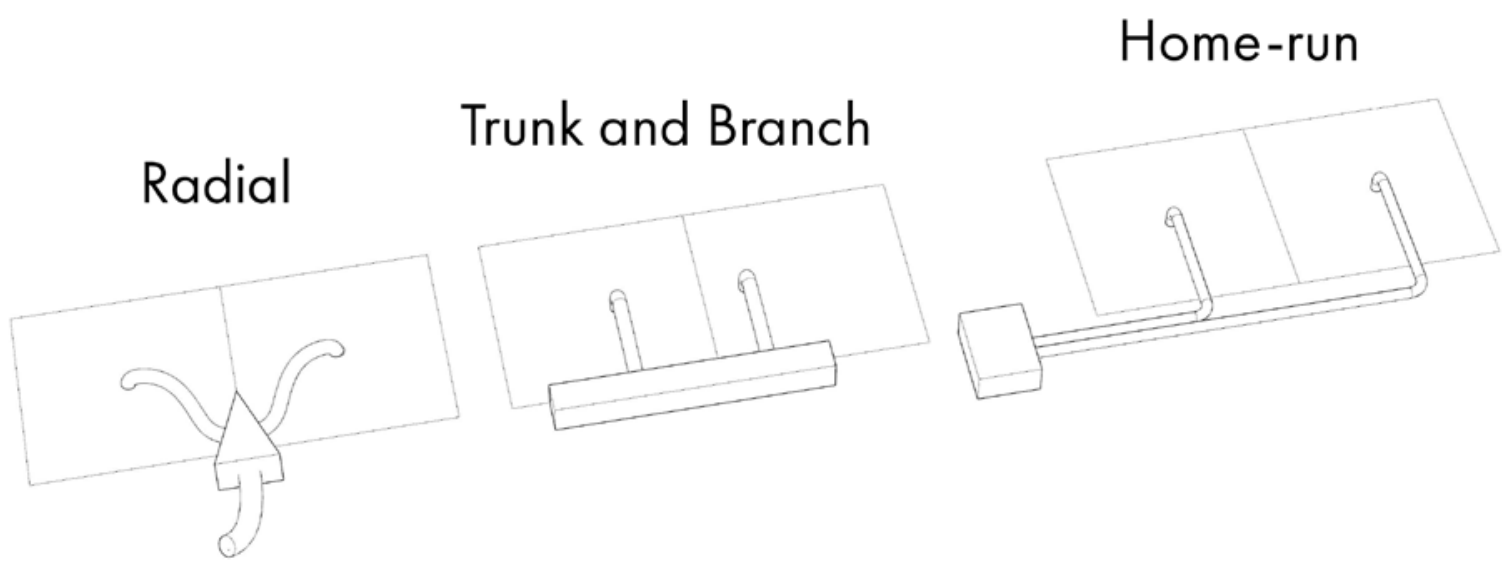

Figure 1. Supply duct topologies

Three room return air scenarios are considered: (1) doors open, (2) doors closed with a 0.75 -in undercut, and (3) doors closed with a large transfer grille. These scenarios were modeled with all return systems; however, providing a transfer grille is redundant and unnecessary for a distributed return, so this scenario was not included.

The following figure illustrates the impact of closing a bedroom partition door. When the door is closed, airflow to the room is reduced, and redirected to an adjacent room on the same splitter box. 

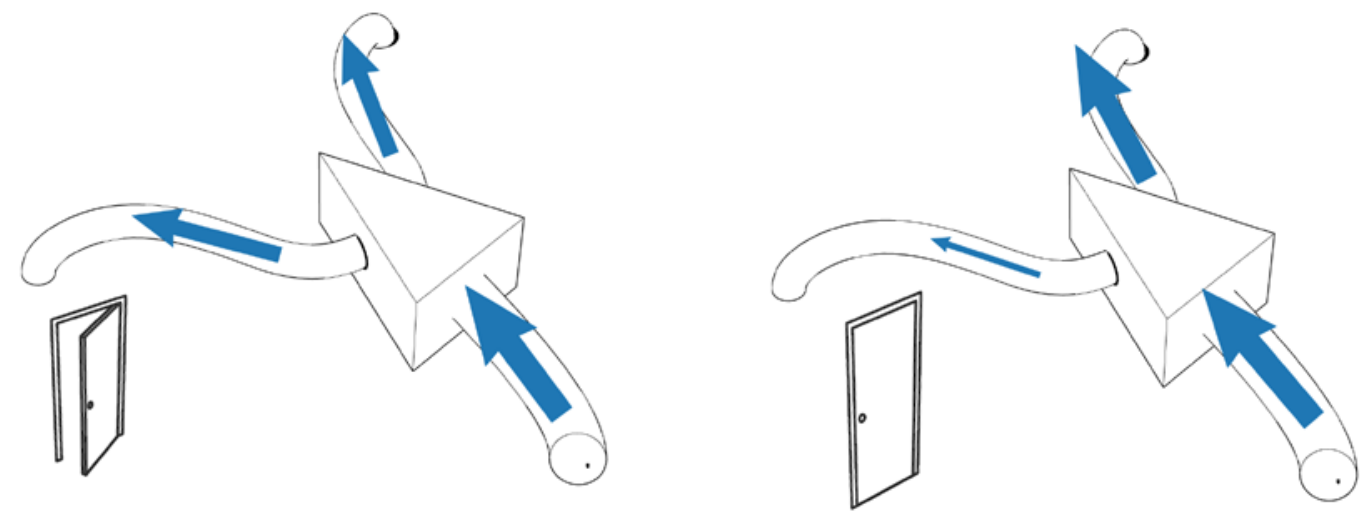

Figure 2. Airflow impact of closed door

\section{Research Methods}

Modeling was completed to develop a better understanding of the airflow implications of closing bedroom doors with different supply and return duct layouts. Airflow models were developed using CONTAM to study this phenomenon and to quantify the impact that different supply and return topologies have on system airflow balance sensitivity. CONTAM is a multizone indoor air quality and ventilation analysis program designed and developed by the National Institute for Science and Technology to model building airflows (NIST 2020). It allows a user to input building geometry, airflow paths, nodes, and environmental parameters, among other inputs. If a complete airflow model is entered into the software, CONTAM will solve the airflow through each path and calculate the pressure at each node based on path resistances. The following figure shows an example of a building and duct layout in CONTAM. 


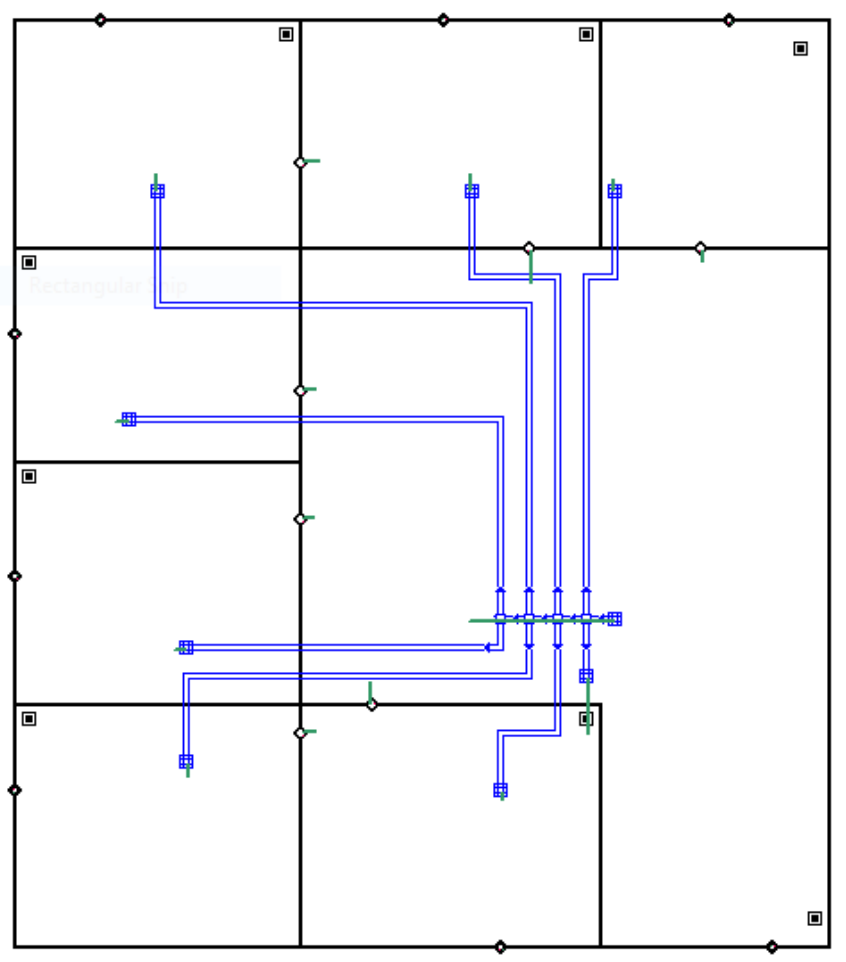

Figure 3. Example building layout in CONTAM. Blue lines denote duct runs, and black lines denote room boundaries. 


\section{Model Description}

Three building layouts were considered in this study: single-story, two-story, and three-story homes. Multiple-story homes were modeled to capture any difference in a single central return vs. a single return on each floor. Room layouts were created based on representative production builder floor plans. Envelope leakage was simulated using a powerlaw: Leakage Area element. Leakage was distributed based on each room's proportion of exterior vertical (walls) or horizontal (ceiling below attic) surface area. Open partition doors were modeled using powerlaw: Orifice elements with a cross-sectional area based on a typical door and a flow exponent of 0.5. Closed partition doors were modeled using a powerlaw: Test Data element to have precise control over the assumed pressure drop and flow relationship. This element takes a single point pressure difference, flow rate, and estimated exponent as input to determine a coefficient for the powerlaw curve. For these models, a pressure difference of 2.5 pascals $(\mathrm{Pa})$ and 50 cubic feet per minute (CFM) was chosen based on test data for a 0.75 -in. x 32-in. door undercut (FSEC 2014). This door width was chosen because it is common on production builder floorplans. Data from other common door widths, such as $30 \mathrm{in}$., would not significantly alter the modeling results. A large transfer grill was simulated by defining a return air path capable of transferring $150 \mathrm{CFM}$ with a $2.5 \mathrm{~Pa}$ pressure difference.

Duct systems were input using the CONTAM duct and junction elements. Within CONTAM, all losses are assumed to occur through the ducts, and junctions act as lossless nodes connecting ducts. Duct flows are modeled using the Darcy Weisbach flow relationship and local loss coefficients. A more detailed description of modeling duct flows can be found in the ASHRAE Fundamentals Handbook (ASHRAE 2005). The air handler unit was modeled using a constant volume fan element, set to a flow rate of $800 \mathrm{CFM}$, the typical airflow when designing to 400 $\mathrm{CFM} /$ ton for a 2.0 ton air conditioner commonly installed in a 2,000- $\mathrm{ft}^{2}$ low-load home. This simplifies the comparisons between duct systems so that changes in total system airflow do not obscure the changes in room airflow. In the real world, the exact airflow would be dictated by the specific equipment installed in the home.

For each supply system, duct sizes were estimated based on airflow and duct length. Duct loss coefficients were input in the range of 2-10, which corresponds to measured data from Lawrence Berkeley National Laboratory (Abushakra et al. 2002). CONTAM's duct balancing capabilities were utilized to determine a terminal loss for each supply register such that a baseline system (all doors open) was balanced within $1 \%$ of design airflow, which is better than most duct systems achieve in the field. The final duct sizing and loss coefficients were adjusted to achieve a typical 0.5 in. of water column (IWC) supply static pressure for each balanced duct system. Having the same static pressure in the main supply plenum eliminates it as a variable impacting the room airflow balance sensitivity. Ducts were assumed to have no air leakage, and to be in conditioned space. The air handler was also assumed to be in conditioned space. 
Each model was run as a steady-state simulation because this study is not evaluating the impact of weather or other environmental impacts. Indoor and exterior temperatures were set to $71^{\circ} \mathrm{F}$, and weather inputs remained constant. An additional scenario was run with the outdoor temperature set to $32^{\circ} \mathrm{F}$, simulating the more extreme winter temperature difference. Increased infiltration was observed, although there was minimal impact on forced HVAC airflows.

Table 1. Building Descriptions

\begin{tabular}{|l|c|c|c|c|c|}
\hline & Floor Area (ft $\left.{ }^{2}\right)$ & Stories & Airflow $\left(\mathrm{ft}^{3} / \mathrm{min}\right)$ & $\begin{array}{c}\text { Leakage Area } \\
\left(\mathrm{in}^{2}\right)\end{array}$ & Rooms \\
\hline Home 1 & 2,000 & 1 & 800 & 27.5 & 8 \\
\hline Home 2 & 2,400 & 2 & 800 & 27.5 & 9 \\
\hline Home 3 & 1,980 & 3 & 800 & 27.5 & 11 \\
\hline
\end{tabular}

For each home, a baseline model was created for each supply and return topology with all partition doors open. A total of 24 baseline models were created, as indicated in the following table. Each of these baseline models was then modified to close a single bedroom door, close the door of the master suite with two rooms, or close all partition doors. This resulted in a total of 96 models.

Table 2. Baseline Models

\begin{tabular}{|c|l|l|}
\hline Home & \multicolumn{1}{|c|}{ Supply } & \multicolumn{1}{c|}{ Return } \\
\hline \multirow{2}{*}{1} & Trunk and Branch & Single Central, Distributed \\
\cline { 2 - 3 } & Radial & Single Central, Distributed \\
\cline { 2 - 3 } & Home-Run & Single Central, Distributed \\
\hline \multirow{4}{*}{2} & Trunk and Branch & Single Central, Central per Story, Distributed \\
\cline { 2 - 3 } & Radial & Single Central, Central per Story, Distributed \\
\cline { 2 - 3 } & Home-Run & Single Central, Central per Story, Distributed \\
\hline \multirow{3}{*}{3} & Trunk and Branch & Single Central, Central per Story, Distributed \\
\cline { 2 - 3 } & Radial & Single Central, Central per Story, Distributed \\
\cline { 2 - 3 } & Home-Run & Single Central, Central per Story, Distributed \\
\hline
\end{tabular}


The following figures show each of the home floor plans, room areas, and target airflows.

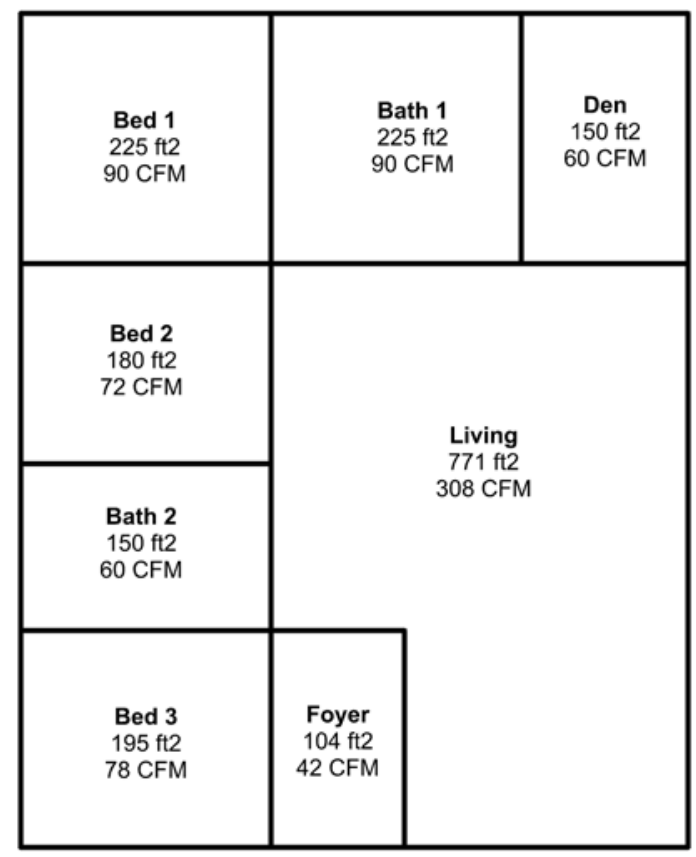

Figure 4. Single-story plan
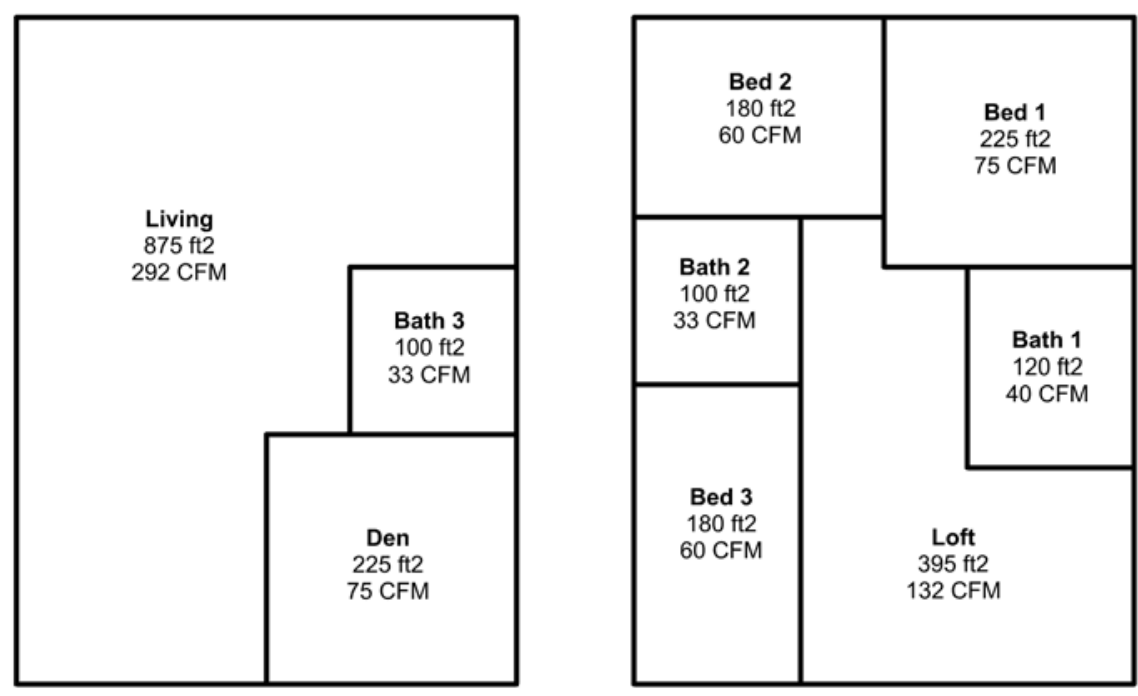

Figure 5. Two-story plan 

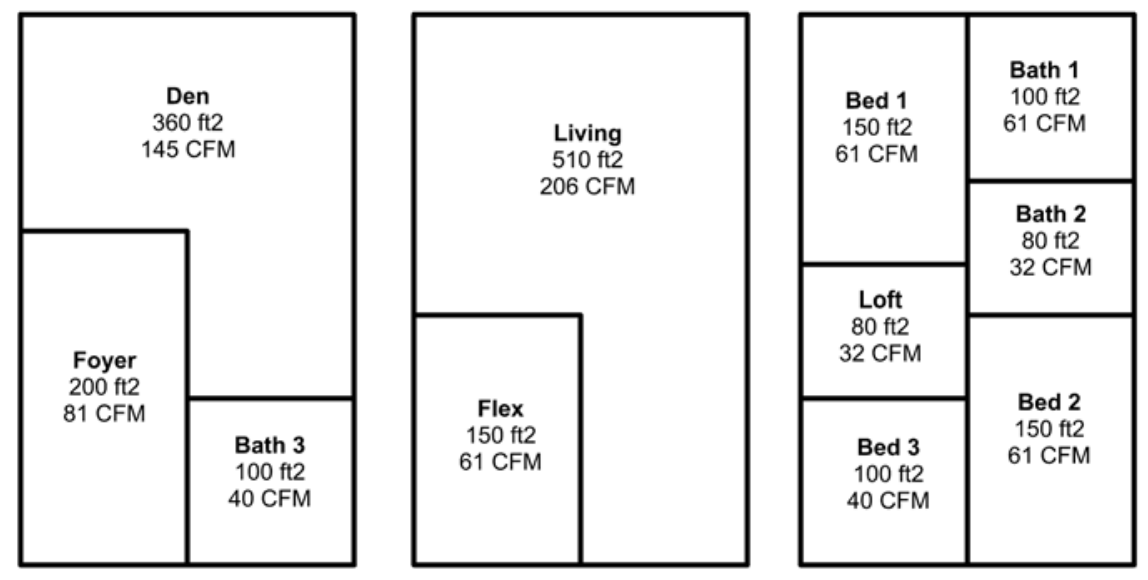

Figure 6. Three-story plan

\section{Results and Discussion}

The following charts show select results of the CONTAM models. In these charts, each room's percent airflow deviation from the balanced baseline is shown. For example, if -2.8 is shown, this means the room's airflow was reduced by $2.8 \%$ when the indicated door was closed. Cells are shaded with green if they show a positive deviation, and purple if they show a negative deviation. Darker colors represent greater deviation. The top of each chart shows the doors that are closed as well as the return type, and the supply type is shown on the bottom for each column. For Home 1, the results for the single central and distributed returns are shown. For Home 2 and 3 (with multiple floors), the results for the single central return are shown, as well as the multifloor returns. The distributed return results were omitted because they showed consistently low percentage differences when doors were closed as there was an adequate return pathway. 


\begin{tabular}{|c|c|c|c|c|c|c|c|c|c|c|c|c|c|c|c|c|c|c|}
\hline \multirow{3}{*}{$\begin{array}{l}\text { Closed: } \\
\text { Return: } \\
\text { Bath1 }\end{array}$} & \multicolumn{6}{|c|}{ Bedroom 2} & \multicolumn{6}{|c|}{ Bedroom 3 + Foyer } & \multicolumn{6}{|c|}{ All Rooms } \\
\hline & \multicolumn{3}{|c|}{ Central } & \multicolumn{3}{|c|}{ Distributed } & \multicolumn{3}{|c|}{ Central } & \multicolumn{3}{|c|}{ Distributed } & \multicolumn{3}{|c|}{ Central } & \multicolumn{3}{|c|}{ Distributed } \\
\hline & 0.2 & 0.3 & 0.2 & 0.0 & -0.1 & 0.0 & 0.5 & 0.5 & 0.5 & 0.1 & 0.0 & 0.1 & -4.3 & -34.3 & -7.5 & -0.5 & -0.9 & -0.9 \\
\hline Bath2 & 0.2 & 0.1 & 0.2 & 0.0 & -0.0 & 0.0 & 0.5 & 0.8 & 0.8 & 0.1 & 0.0 & 0.1 & 1.0 & 0.9 & 1.2 & 0.2 & 0.6 & 0.3 \\
\hline Bed1 & 0.2 & 0.4 & 0.2 & 0.0 & -0.1 & 0.0 & 0.5 & 0.5 & 0.5 & 0.1 & 0.0 & 0.1 & -4.3 & -5.4 & -5.9 & -0.5 & -0.3 & -0.7 \\
\hline Bed2 & -1.5 & -2.8 & -1.8 & -0.1 & 0.7 & -0.1 & 0.5 & 0.5 & 0.5 & 0.1 & 0.0 & 0.1 & 0.4 & 0.3 & 0.3 & 0.1 & 0.7 & 0.2 \\
\hline Bed3 & 0.2 & 0.1 & 0.2 & 0.0 & -0.0 & 0.0 & -2.8 & -2.9 & -2.9 & -0.4 & -0.0 & -0.4 & -1.5 & -1.8 & -1.7 & -0.2 & -0.1 & -0.3 \\
\hline Den & 0.2 & 0.3 & 0.2 & 0.0 & -0.1 & 0.0 & 0.5 & 0.5 & 0.5 & 0.1 & 0.0 & 0.1 & 0.7 & -1.7 & -2.6 & 0.1 & 2.7 & 0.0 \\
\hline Foyer & 0.2 & 0.1 & 0.2 & 0.0 & -0.0 & 0.0 & -2.8 & -2.9 & -2.9 & -0.4 & -0.0 & -0.4 & -1.5 & -1.8 & -1.7 & -0.2 & -0.1 & -0.3 \\
\hline Living - & 0.2 & 0.3 & 0.2 & 0.0 & -0.1 & 0.0 & 0.5 & 0.5 & 0.5 & 0.1 & 0.0 & 0.1 & 2.7 & 12.4 & 4.8 & 0.3 & -0.4 & 0.5 \\
\hline Supply & 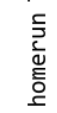 & \begin{tabular}{l}
-7 \\
$\pi$ \\
$-\pi$ \\
$\pi$ \\
$\pi$ \\
\multicolumn{5}{|c}{}
\end{tabular} & ָૃ & 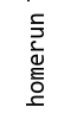 & \begin{tabular}{l}
$-\vec{\pi}$ \\
$\stackrel{-1}{0}$ \\
$\frac{\pi}{\pi}$ \\
\multicolumn{2}{c}{}
\end{tabular} & مَ & 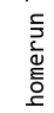 & 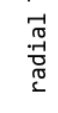 & حָ & 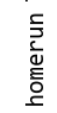 & 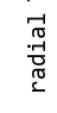 & ָָ & 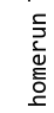 & $\begin{array}{l}\stackrel{\pi}{\pi} \\
\stackrel{-\pi}{\sigma} \\
\frac{\pi}{5}\end{array}$ & 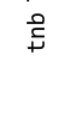 & 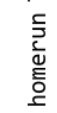 & 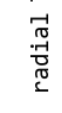 & مُ \\
\hline
\end{tabular}

Figure 7. Home 1 (single story) simulation results

\begin{tabular}{|c|c|c|c|c|c|c|c|c|c|c|c|c|c|c|c|c|c|c|}
\hline \multirow{3}{*}{$\begin{array}{l}\text { Closed: } \\
\text { Return: } \\
\text { Bath1 }\end{array}$} & \multicolumn{6}{|c|}{ Bedroom 2} & \multicolumn{6}{|c|}{ Bedroom 1 + Bath 1} & \multicolumn{6}{|c|}{ All Rooms } \\
\hline & \multicolumn{3}{|c|}{ Central } & \multicolumn{3}{|c|}{ Multi } & \multicolumn{3}{|c|}{ Central } & \multicolumn{3}{|c|}{ Multi } & \multicolumn{3}{|c|}{ Central } & \multicolumn{3}{|c|}{ Multi } \\
\hline & 0.1 & 0.1 & 0.2 & 0.1 & 0.1 & 0.2 & -2.6 & -4.4 & -4.3 & -2.6 & -4.4 & -4.2 & -2.4 & -4.0 & -3.9 & -2.4 & -4.0 & -3.8 \\
\hline Bath2 & 0.1 & 0.3 & 0.3 & 0.1 & 0.3 & 0.3 & 0.4 & 0.7 & 1.3 & 0.4 & 0.7 & 1.3 & 0.3 & 0.6 & 1.1 & 0.3 & 0.6 & 1.1 \\
\hline Bath3 & 0.1 & 0.1 & 0.1 & 0.1 & 0.1 & 0.1 & 0.4 & 0.7 & 0.6 & 0.4 & 0.7 & 0.6 & 0.4 & 1.0 & 0.3 & 0.4 & 1.0 & 0.3 \\
\hline Bed1 & 0.1 & 0.1 & 0.3 & 0.1 & 0.1 & 0.3 & -2.6 & -4.4 & -4.6 & -2.6 & -4.4 & -4.6 & -2.4 & -4.0 & -4.1 & -2.4 & -4.0 & -4.1 \\
\hline Bed2 & -1.0 & -1.9 & -1.9 & -1.0 & -1.9 & -1.9 & 0.4 & 0.7 & 1.3 & 0.4 & 0.7 & 1.3 & -0.4 & -0.8 & -0.3 & -0.4 & -0.8 & -0.3 \\
\hline Bed3 & 0.1 & 0.2 & 0.1 & 0.1 & 0.2 & 0.1 & 0.4 & 0.7 & 0.8 & 0.4 & 0.7 & 0.8 & -0.4 & -1.5 & -0.6 & -0.4 & -1.5 & -0.6 \\
\hline Den & 0.1 & 0.1 & 0.1 & 0.1 & 0.1 & 0.1 & 0.4 & 0.7 & 0.6 & 0.4 & 0.7 & 0.6 & -1.1 & & -2.3 & -1.1 & & -2.3 \\
\hline Living & 0.1 & 0.1 & 0.1 & 0.1 & 0.1 & 0.1 & 0.4 & 0.7 & 0.6 & 0.4 & 0.7 & 0.6 & 0.9 & 1.8 & 1.5 & 0.9 & 1.8 & 1.5 \\
\hline Loft & 0.1 & 0.2 & 0.1 & 0.1 & 0.2 & 0.1 & 0.4 & 0.7 & 0.8 & 0.4 & 0.7 & 0.8 & 0.9 & 1.9 & 1.5 & 0.9 & 1.9 & 1.5 \\
\hline Supply: & 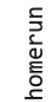 & 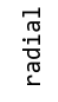 & זُ & 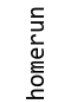 & 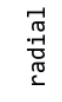 & ڤُ & 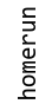 & 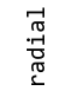 & ॄ् & 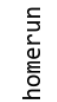 & 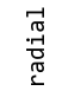 & ॄॄ & 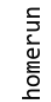 & 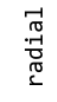 & $\stackrel{\cap}{+}$ & 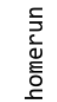 & 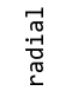 & $\stackrel{\circ}{c}$ \\
\hline
\end{tabular}

Figure 8. Home 2 (two stories) simulation results 


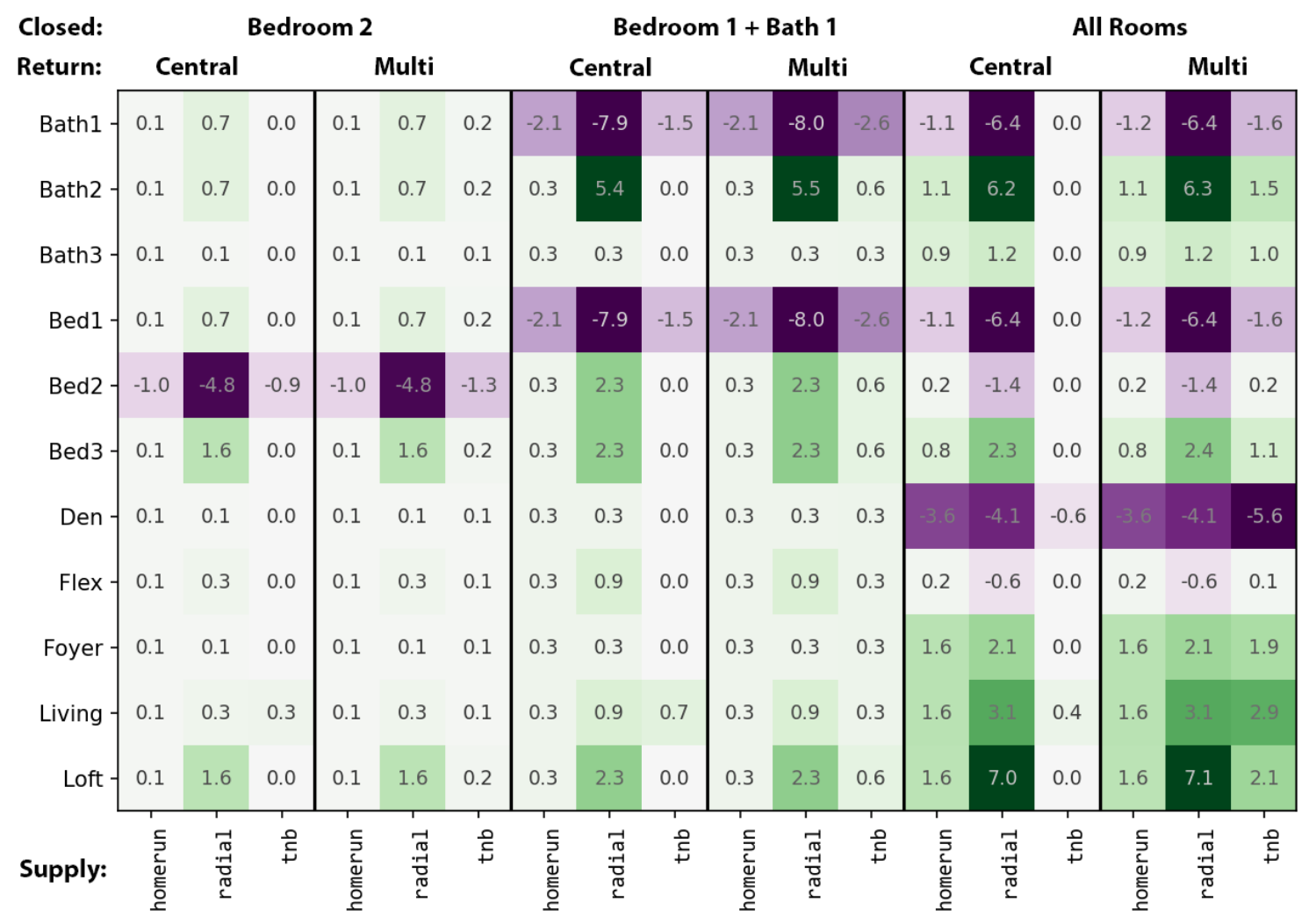

Figure 9. Home 3 (three stories) simulation results

Each of the home models showed the expected behavior - that a distributed return, with a return duct to every room, is least sensitive to changes in return pathway. Between the central return cases (single and one per floor), there was only a small difference in airflow. This is in part due to oversizing the returns to ensure minimal airflow resistance. From the perspective of the model, the complete return airflow pathway resistance was similar in either case. The majority of the airflow resistance is from the closed bedroom door, not the central ductwork. In practice, installing oversized returns to every room would not be practical, and is the reason to consider using a central return strategy. Also, although the airflow balance is not impacted by using a single central return or a central return on each floor, actual comfort conditions may be impacted due to vertical thermal stratification.

With the central return models, closing a single bedroom door most clearly showed the difference between supply topologies. In each central return case, the home-run system maintained airflow balance better than the radial system. The trunk and branch system performed similar to the home-run system in Homes 1 and 3, but similar to the radial system in Home 2. For example, in Home 3 Bedroom 2, the radial system showed $4.8 \%$ less airflow compared to $1.0 \%$ less airflow for the home-run system. Although this difference is unlikely to have a real-world impact, if the return path is twice as constricted (25 CFM at 2.5 PA), then the difference grows to $12.4 \%$ and $2.8 \%$, respectively. Restricted undercuts can occur for several reasons including: new carpet or rugs and incorrectly installed or new bedroom doors. The home-run system also shows 
an even redistribution of airflow to all other supply runs. This is expected because all runs emanate from a central manifold that is at a uniform static pressure. With the radial and trunk and branch systems, the airflow is unevenly redistributed, with the rooms connected to other ducts on the end of the branch showing the largest increase in airflow. For example, in Home 3 when the Bedroom 2 door is closed, each other room gets an extra $0.1 \%$ airflow for the home-run system, while the rooms show an uneven redistribution for the radial and trunk and branch systems. These compounding effects will negatively impact temperature uniformity in a home, reducing comfort for the occupants.

The largest magnitude airflow change was for Home 1 Bath 1 with a radial supply system and central return system. In this case, the supply for Bath 1 was from a separate splitter box than the supply for Bedroom 1, which is an adjacent room. When Bedroom 1's door was closed, it included the bath space. Because the splitter box serving Bedroom 1 was at a higher pressure than the box serving Bath 1, it overpowered the flow potential into Bath 1.

Home 3, with three levels, generally exhibited the greatest sensitivity to different return air scenarios. This is likely due to the more complex supply and return systems serving each floor. There is also more pressure loss along duct route as you move away from the air handler unit, which means the pressure available at the final split is lower than for the two- or one-story homes. Lower pressure at the final split results in greater sensitivity to airflow imbalances.

The magnitude of the airflow sensitivity is dependent on a number of assumptions in the building model, such as room supply airflow and return path resistance. These models accurately capture the directional differences between the systems; however, a more thorough evaluation that includes real-world test data could be used to calibrate duct parameters and loss coefficients. The magnitude of the flow differences may increase or decrease in the real world, but this work suggests that there is a trend that design practitioners should consider.

Models with a large transfer grille in addition to the door undercut were run and analyzed, but not shown as they consistently showed less than $1 \%$ impact on airflow regardless of supply or return strategy. This reinforces the established industry practice that a properly sized transfer grille can reduce supply airflow imbalances.

The following table shows the static pressure in the final supply split of each air distribution system for Home 1 with a central return and all doors open.

Table 3. Static Pressure in the Final Split

\begin{tabular}{|c|c|}
\hline Supply System & $\begin{array}{c}\text { Final Split Static Pressure } \\
\text { (IWC) }\end{array}$ \\
\hline Radial Splitter Box & 0.25 \\
\hline Trunk and Branch & 0.35 \\
\hline Home-Run & 0.5 \\
\hline
\end{tabular}


As expected, the radial splitter box design has the lowest available static pressure to the final length of duct. The lower available pressure to overcome resistance in the return path is a primary reason that a sequentially splitting or branching duct system is more sensitive to return resistance.

\section{Conclusions}

Consistent HVAC airflow balance is important in a building to maintain comfort and reduce the risk of durability issues and increased infiltration. The results of this study indicate that different supply and return strategies can be effective if properly executed. However, because of cost and space constraints, some strategies may be difficult to implement in practice.

The results of this study indicate that a home-run duct system is less sensitive to changes in the return pathway via closing partition doors. If a room return transfer path of sufficient size is provided to each room, the difference in airflow can be considered negligible. This means that builders and contractors can be more confident in balanced airflow, and thermal uniformity, with a home-run system. Using a trunk and branch or splitter box supply layout can also yield satisfactory balance with a central return, although more care must be made in selecting and sizing the room return air pathway.

The results show that a distributed return will maintain supply airflow balance even when partition doors are closed. Practically, it is difficult to install low-resistance dedicated return ducts in conditioned space. Oversized distributed returns will offer the best airflow balance with doors closed; however, they are rarely installed this way, and typically result in an increased total system static pressure. Additionally, they cost more to install and are difficult to integrate within a home's structure.

These modeled results rely on a number of assumptions about the return and supply duct system. The airflow model employed by CONTAM is a simplified representation of complex flow phenomenon. These results are based on isothermal conditions, with the supply air, room air, and outdoor air being the same temperature. In a real home, with HVAC equipment operating, these will all be at different temperatures, impacting airflow and comfort. Although the results show an airflow balance trend, an important next step is to compare these results to field and lab experiments evaluating other comfort variables to validate the findings. 


\section{References}

Abushakra, Bass, lain Walker, and Max Sherman. 2002. "A Study of Pressure Losses In Residential Air Distribution Systems." Presented at the 2002 ACEEE Summer Study on Energy Efficiency in Buildings, Pacific Grove, CA. Lawrence Berkeley National Laboratory. LBNL-49700.

https://www.aceee.org/files/proceedings/2002/data/papers/SS02_Panel1_Paper01.pdf.

ACCA. 2016. Residential Duct Systems: Manual D. Alexandria, VA: Air Conditioning Contractors of America.

ASHRAE. 2017. ASHRAE Handbook of Fundamentals. Atlanta, GA: ASHRAE.

Fonorow, Ken, Dave Jenkins, Stephanie Thomas-Rees, and Subrato Chandra. 2010. "Low Cost Interior Duct Systems for High Performance Homes in Hot Climates." Presented at the 2010 ACEEE Summer Study on Energy Efficiency in Buildings, Pacific Grove, CA. FSEC-PF-45110. http://www.fsec.ucf.edu/en/publications/pdf/FSEC-PF-451-10.pdf.

FSEC. 2014. Return Air Pathway Study. FSEC for the U.S. Department of Energy Building America Partnership for Improved Residential Construction (BA-PIRC). http://www.bapirc.org/casestud/return_air/index.htm.

Lubliner, Michael, Ryan Kerr, Andy Gordon, and Chuck Murray. 2008. "Moving Ducts Inside: Big Builders, Scientists Find Common Ground.” Presented at the 2008 ACEEE Summer Study on Energy Efficiency in Buildings, Pacific Grove, CA. Washington State University. http://www.energy.wsu.edu/documents/aht_aceee\%20ducts\%20inside\%5B1\%5D.pdf.

NIST. 2020. CONTAM 3.4.0.0. Gaithersburg, MD: National Institute of Standards and Technology. https://www.nist.gov/services-resources/software/contam.

NREL. 2006. Building America Residential System Research Results: Achieving 30\% Whole House Energy Savings Level in Cold Climates. National Renewable Energy Laboratory for the U.S. Department of Energy Building America Program. NREL/SR-550-38783.

https://www.nrel.gov/docs/fy07osti/39743.pdf. 


\section{usourarer ENEROY}

Office of

ENERGY EFFICIENCY \&

RENEWABLE ENERGY
For more information, visit: energy.gov/eere/buildings 